\title{
Heuristic dynamic approach to perishable products in presence of deterioration effect
}

\author{
Raghad O. Bahebshi and Abdulaziz T. Almaktoom* \\ Department of Operations and Information Management, Effat University, PO Box 34689, Jeddah 21478, \\ Kingdom of Saudi Arabia
}

Received: 12 February 2019 / Accepted: 17 May 2019

\begin{abstract}
Joining warehouses and suppliers facilities to deliver the finished product to the end customer is a complex process that requires extensive consideration. The resulting chain is an integration of such entities as the supplier, manufacturer, distributor, warehouse, retailer, and end customer. A perishable product is any product that can rot, spoil, or deteriorate rapidly and, soon after manufacture, may become unusable or obsolete. Perishable products thus have special nutritional characteristics that necessitate care and unique treatment for them. Such products can be anything that becomes outdated a short time after production or harvest, such as fruits, vegetables, meat, certain drinks, blood, and pharmaceuticals. The objective of this study is to find the best heuristics for distributing multiple perishable products as early as possible to maximize profit. Case studies involving featuring perishable products at different rates of degradation with multiple retailers and limited transportation capacity were carried out to demonstrate the effectiveness of the proposed method.
\end{abstract}

Keywords: Dynamic pricing / logistics / optimization / supply chain

\section{Introduction}

This paper is an extended version of a previous paper presented at the 7 th Annual Conference on Industrial Engineering and Operations Management [1], and significantly expands the model and case studies presented therein. The term "supply chain" has many definitions but, in general, all of them represent the same objective: to either maximize total profit or simultaneously minimize cost and waste. The supply chain is an integration of many entities, including the supplier, distribution centers, retailers, and the end-customers. One of the three degrees of supply chain complexity mentioned by research in [2] is the direct supply chain. It refers to the set or network of three or more items that flow from the source to the end customer, such as products, services, finance, and/or information. In the manufacturing industry, this network consists of suppliers, manufacturers, plants, inventories, warehousing, distribution centers, and retailers. Performance is important in the supply chain to obtain the best linkage among all entities, especially when trading globally. Uncertainty is among the most severe problems that can corrupt the entire supply chain [3-9]. Therefore, routing the supply chain is challenging with respect to cost and

\footnotetext{
* e-mail: abalmaktoom@effatuniversity.edu.sa
}

customer satisfaction. Many companies focus on different aspect of the supply chain to reduce cost and maintain efficient services.

Coordination among members of the supply chain is critical in distributing perishable products [10]. Poor supply chain management can lead to significant financial loss [11,12], especially when distributing perishable products such as dairy, fresh fruits, fresh flowers, and live seafood because freshness in this case has a direct impact on price and customer satisfaction. Many studies have stressed the important of the timely distributing and delivery of perishable products [13], given that $20-60 \%$ of all perishable products are lost in the supply chain [14]. Models and techniques to improve the supply chain should thus consider the finite lifetime of perishable products. This paper considers dynamic perishable products for which the retailers may have multiple orders with varying shelf lives.

\subsection{Physical deterioration vs. value deterioration}

Deterioration is the continuous degradation for any perishable commodity, and may have a significant effect on the entire supply chain. However, preserving goods in the best condition in terms of temperature and proper storage reduces the risk of their becoming unusable, and, hence, can minimize total cost. Many studies have examined the rate of deterioration of perishable products 
based on different factors. Physical changes to any perishable food can be noticed by for instance, odor, color, and taste. In addition, changes can be detected using its economic value, for example, dollar cost and market value. Therefore, it is sometimes challenging to determine the rate of degradation because of the many criteria involved in its measurement. The degradation of a product adversely affects customer behavior and willingness to pay (WTP). Therefore, sellers adjust their prices according to the major factors influencing dynamic pricing [15].

Many studies have explored the impact of the deterioration of vegetables using different techniques. For example, authors in [16] considered deterioration as a reduction in the value and quality of vegetables during dispatch from distributor to retailers. However, when quality of vegetables continually drops, the entire supply chain suffers a significant loss. To illustrate, researchers formulated a model that is a combination of the vehicle routing problem with time windows and time-dependent travel times (VRPTWTD) to solve the distribution problem by using a heuristic approach - tabu search in the presence of some characteristics of perishable items. They defined quality as a criterion and considered it in the model to minimize the total cost of distribution by considering the number of vehicles, distance, and loss in the quality of the product [16]. Another study in by Chen et al. categorized deterioration into two types [17]. The first type becomes outdated at the end of the planning horizon and the second type features deterioration throughout the cold chain process. As the above authors have claimed, this second kind of deterioration can be further divided into two levels: (1) fixed shelf life and (2) continuous decay [17]. They proposed a combination model for scheduling and delivering perishable products. The model was formulated as a production scheduling and vehicle routing problem with time windows for perishable goods (PS-VRPTW-P). The objective function of their model maximizes total profit to the supplier by identifying when to produce the appropriate quantity at the appropriate time and dispatch the consignment at minimal cost [17].

In 2009, Blackburn and Scudder determined the loss in the value of perishable products over time by using the marginal value of time (MVT) [18]. A literature review in [19], claimed that most publications in the area had assumed the rate of deterioration to be constant and few had considered that it may change exponentially. Deterioration is among the most common causes of waste in the transportation process but scant attention has been paid to it in the literature. Authors in [20] determined the decay rate by considering the loss in the quality of the product over the time. However, the degradation in quality was modeled using many variables during the storage and transport periods. A study in [21] formulated a model for the both quality and quantity of perishable product but considered product degradation throughout the transportation process (quality decline) as well as the obsolescence responsible for a reduction in quantity. In [22] researchers claimed that the deterioration of perishable items can be classified into two levels: the item itself decaying until it becomes outdated, and the loss of value due to such factors as season or technology. According to Raafat there are different concepts of deteriorating inventory. However, during the planning horizon, some products decay over time and accordingly have a fixed lifetimes whereas others have variable lifetimes. When products are no longer useable, rendered obsolete at the end of the season or planning horizon, this is another kind of deterioration in inventory [23].

\subsection{Modeling perishable products}

Many important contributions have been made to modeling the supply chain of perishable products, and many studies have considered the vehicle routing problem (VRP) and the distribution of perishable products. In 1986 , Fedegruen et al. developed a model to minimize the cost of the transportation, shortage, and obsolescence of perishable products. They focused on perishable foods transported from a central depot to a set of retailers [24].

Research in [25] extended the traditional VRP to the open multi-depot vehicle routing problem (OMDVRP). However, this model is a combination of the open vehicle routing problem (OVRP) and the MDVRP. They proposed it to deal with a distribution problem in Athens, Greece. To solve for the distribution of fresh meat from different depots to many customers, they used a metaheuristic called the list-based threshold-accepting (LBTA) algorithm.

Also [26], extended the vehicle routing problem with time windows (VRPTW) by considering some characteristics of perishability during the dispatching process. They devised the stochastic vehicle routing problem with time window (SVRPTW) to minimize total cost, which makes their model more efficient and valuable than the traditional VRPTW. Because they included inventory and the cost of energy in their calculation, their results showed a significant reduction in cost during delivery. Research in [27] presented a mixed-integer programming model and proposed a heuristic algorithm to solve for the distribution of perishable products between a vendor and a retailer. They yielded effective results in terms of minimizing the total costs of transportation and inventory associated with frequent deliveries between vendor and customer. In [28], Xunyu and Tomohiro proposed a model for delivering and scheduling perishable products to satisfy the customer and minimize total expected cost. They developed a metaheuristic genetic algorithm to provide a solution for minimizing the total cost associated with production and scheduling. Authors in [29], introduced a two-echelon location routing problem with time windows (2E-LRPTW) for a sustainable design of the supply chain network (SCN) to optimize economic and environmental objectives in the context of perishable foods. The goal of the 2E-LRPTW is to determine the number and locations of facilities, and to optimize the quantity of products delivered.

Perishable goods tend to rot, spoil, or deteriorate rapidly, and thus may become unusable or obsolete. Therefore, logistics for perishable goods, which have special nutritional characteristics, require paying close attention to them. Most past research did not consider fresh vegetables because of their rapid rate of degradation and difficulties in including the dynamic degradation effect on 
the vegetables prices into the design optimization process. Thus, the authors focus here on developing a method that can minimize the cost of transport of fresh vegetables while including degradation effect in the model. This will help in being able to minimize total cost and waste, and to accordingly ensure customer satisfaction. Also, the model considers the integration of multiples entities such as the grower (farm), packing shade, distribution center (wholesaler), retailer, and end customer. Results of solving the model will help decision maker in the supply chain management department to find the best way of distributing multiple types of perishable goods as early as possible to minimize the total cost to the wholesaler, satisfy customers, and fulfill the required demand. The remainder of this paper is organized as follows: Section 2 defines and formulates the problem, and Section 3 presents multiple case studies to illustrate the effectiveness of the proposed methodology. The conclusion of this study is provided in Section 4.

\section{Problem description}

\subsection{Problem formulation}

This study focuses on distributing multiple kinds of perishable products from a central distribution facility to retailers. Because these products are perishable, time is of the essence. Therefore, this paper considers some characteristics of perishability, such as the rate of deterioration and shelf life, to extend the traditional VRP. There are five distribution or delivering techniques: (1) direct shipment based on the highest daily rate; (2) direct shipment based on shelf life; (3) direct shipment based on the highest selling price; (4) grouping the most profitable products and shipping to the nearest neighbor; and (5) shipping one type of product at the time to the nearest neighbor.

We consider a central depot distributing multiple kinds of perishable products with different shelf lives. Further, we assume that the demands of the retailers are deterministic, and that total demand and supply are in equilibrium such that there is no shortage or backorder. The distance between the depot and each retailer is known, as is the distance between retailers. However, the travel time is determined as the distance divided by the average speed of the vehicle plus two hours as variation time. The vehicles are assumed to travel at a constant speed, and the capacity for each vehicle is limited. However, the total number of vehicles is determined as the total demand divided by vehicle capacity. The transportation cost is determined as a certain amount in dollars per mile per vehicle load.

The cold chain in this case works to distribute multiple kinds of perishable products from a distribution center (DC) to a set number of retailers. The DC is responsible for the total cost of shipment to all retailers.

\subsection{Objective}

The objective of this study is to find the best means of distributing multiple kinds of perishable products as early as possible to maximize total profit. Satisfying customers and fulfilling their demands without loss is the aim of the proposed model. To maintain product quality, we need to find the fastest way to satisfy all demand as soon as possible to avoid increasing cost.

\subsection{Methodology}

In this research, it is assumed that values of perishable products change based on two dynamical variables over time. The first is the selling price, and is based on shelf life and the day of sale. The second variable is transportation cost, and is based on the number of the products shipped in a day. These variables significantly influence profit. To be able to evaluate the value of each perishable products over time and calculate total profit of the DC equations (1)-(5) been developed.

Step 1. Identify the shelf life of each degradable item.

Step 2. Calculate the selling price of each product. The price of each product decreases over time until it reaches zero on the last day of its shelf life. The selling price of each product can be calculated using equation (1):

$$
S_{n, d}=T S_{n}-\left(\left(\frac{d_{n}}{s h_{n}}\right) * T S_{n}\right),
$$

$S_{n, d}$, the selling price of product $(n)$ on day $(d) ; T S_{n}$, the targeted selling price of product $(n) ; S h_{n}$, the shelf life of product $(n)$; and $d_{n}$, the day on which product $(n)$ is sold.

Step 3. Define and calculate total cost:

i. Calculate transportation cost (TS) by using equation (2):

$$
T S=\sum_{k=1}^{K} y_{r}^{k}+C^{k} * d i s_{i j}
$$

$T S$, transportation cost; $C^{k}$, the cost of vehicle $k$ traveling per mile from node $i$ to node $j ; d i s_{i j}$, distance between node $i$ and node $j$; and $y_{r}^{k}$, additional charges associated with vehicle $k$ traveling from node $i$ to node $j$.

ii. Calculate the total cost, including the cost of the product and transportation. The total cost (TC) is calculated using equation (3):

$$
T C=T S+P C
$$

$T C$, total cost; $T S$, transportation cost; and $P C$, product cost that represents the cost of production plus handling and storage.

Step 4. Calculate revenue by calculating the quantity of each type of product sold on day $(d)$ multiplied by the selling price of the same product type on day $(d)$ :

$$
R e v_{n, d}=\sum_{n=1}^{N} \sum_{d=1}^{D} P_{n, d} * S_{n, d}
$$

$R e v_{n, d}$, revenue from selling product $(n)$ on day $(d) ; P_{n, d}$, product $(n)$ sold on day $(d) ; S_{n, d}$, selling price of product $(n)$ on day $(d)$. 
Step 5. Calculate total profit $(T P)$ by subtracting $T C$ from revenue $(R e v)$ as shown below:

$$
T P=R e v_{n, d}-T C,
$$

$T P$, total profit; $R e v_{n, d}$, revenue by selling product $(n)$ on day $(d)$; and $T C$, total cost.

\subsection{Assumptions}

- There is only one central depot $D C$ and many retailers $R_{m}$.

- The supplier is not considered in this model.

- There are multiple types of products, and each has its own shelf life.

- The total supply and total demand are assumed to be in equilibrium so that there is no shortage or backorder.

- There is no return policy between the distributor and retailers.

- The vehicles are homogeneous, with known capacities.

- There is a restricted fleet of vehicles.

- Each retailer is visited only once, and its demand has to be satisfied.

- All retailers visited have total demand less than or equal to the vehicle's capacity.

- Each vehicle is assumed to be driven at constant speed.

- The total number of working hours in a day is eight (one shift only).

- The travel time is determined by distance and speed.

- The service time is assumed to be constant for each retailer.

- The fixed cost of ordering is obsolete in this model.

- The time window is obsolete.

\subsection{Mathematical model}

$$
\begin{array}{ll}
\text { Max. } & T P=R e v_{n, d}-T C \\
\text { s.t. } & \\
& \operatorname{Rev}_{n, d}=\sum_{n=1}^{N} \sum_{d=1}^{D} P_{n, d} * S_{n, d} \\
& T C=T S+P C \\
& T S=\sum_{k=1}^{K} y_{r}^{k}+C^{k} * d i s_{i j} \\
& S_{n, d}=T S_{n}-\left(\left(\frac{d_{n}}{s h_{n}}\right) * T S_{n}\right) \\
& S h_{n} \geq 0 \\
& S_{n, d} \geq 0 \\
y_{r}^{k} \geq 0 \\
\text { dis } s_{i j} \leq d i s_{i j}^{U} \\
k_{c a p} \leq k_{c a p}^{U}
\end{array}
$$

\subsection{Procedure of calculations}

This sub-section illustrates the procedure used for spreadsheet calculations. We explain all delivery techniques even though there are some similarities among them.

\subsubsection{Direct shipment based on highest daily rate $(M 1)$}

- Find the highest rate of profit of all products using equation (7):

$$
\text { Profit rate }=S_{n, d}-S_{n, d+1}
$$

- Sort products from the most profitable to the least.

- Compute the total number of working hours a day.

- Compute the distance between the DC and the first retailer.

- Convert distance into time using equation (8):

$$
\text { Delivery time }=\frac{\text { Distance to retailer }}{\text { Constant speed }}
$$

- Add service time to delivery time.

- Compute total time.

- Total delivery time $=$ service time + delivery time.

- Back time $=$ delivery time.

- Total loading time = total delivery time + back time.

- Start dispatching products to each retailer separately.

- Compute the total number of remaining hours = total number of working hours - total number of hours to load.

- Calculate the profit made on the same day using equation (5).

- If the remaining time $\leq$ total loading time, make another trip.

- Otherwise, start delivery on the day next.

- Repeat starting from step 4 until all products have been delivered.

\subsubsection{Direct shipment based on shelf life (M2)}

- Sort the products based on shelf life from shortest to longest.

- Compute the total number of working hours a day.

- Compute the distance between the DC and the first retailer.

- Convert distance into time using equation (8).

- Add service time to delivery time.

- Compute total time.

- Total delivery time $=$ service time + delivery time.

- Back time $=$ delivery time.

- Total loading time = total delivery time + back time.

- Start dispatching products to each retailer separately.

- Compute the total number of remaining hours = total number of working hours - total number of hours used to load.

- Calculate profit on the same day using equation (5).

- If the remaining time $\leq$ the total loading time, make another trip.

- Otherwise start delivery on the day next.

- Repeat starting from step 4 until all products have been delivered.

\subsubsection{Direct shipment based on the highest selling} price $(M 3)$

- Sort products from the highest selling price to the lowest. - Compute the total number of working hours a day. 
- Compute the distance between the DC and the first retailer.

- Convert distance into time using equation (8).

- Add service time to delivery time.

- Compute the total time.

- Total delivery time $=$ service time + delivery time.

- Back time $=$ delivery time.

- Total loading time $=$ total delivery time + back time.

- Start dispatching products to each retailer separately.

- Compute the total number of remaining hours = total number of working hours - total number of hours used to load.

- Calculate profit on the same day using equation (5).

- If the remaining time $\leq$ the total loading time, make another trip.

- Otherwise, start delivery on the day next.

- Repeat starting from step 4 until all products have been delivered.

\subsubsection{Grouping the most profitable products and shipping} to the nearest neighbor (M4)

- Find the highest ratio of profit for all products using equation (7).

- Sort products from the most profitable to the least.

- Compute the total number of working hours a day.

- Compute the distance between the DC and the first retailer.

- Convert distance into time using equation (8).

- Add service time to delivery time.

- Compute the total time.

- Total delivery time $=$ service time + delivery time.

- Back time $=$ delivery time.

- Total loading time $=$ total delivery time + back time .

- Dispatch the most profitable product based on the sorting toward the nearest retailer its demand is satisfied.

- Deliver the same most profitable product to the secondnearest retailer, and so on.

- When the most profitable product has been delivered, start with the second-most profitable one and deliver it to the nearest neighbor, and so on.

- Compute the total number of remaining hours = total number of working hours - total number of hours used to load.

- Calculate profit on the same day using equation (5).

- If the remaining time $\leq$ total loading time, make another trip.

- Otherwise, start delivery on the day next.

- Repeat starting from step 4 until all products have been delivered.

\subsubsection{Shipping products by entire fleet to the nearest neighbor (M5)}

- Find the highest ratio of profit for all products using equation (7).

- Compute the total number of working hours a day.

- Sort the products from the most profitable to the least.

- Compute the distance between the DC and the first retailer.

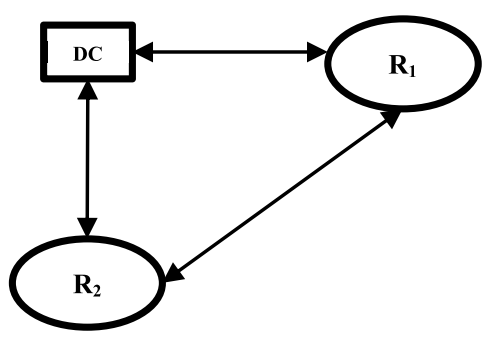

Fig. 1. Supply chain network.

- Convert distance into time using equation (8).

- Add service time to delivery time.

- Compute the total time.

- Total delivery time $=$ service time + delivery time .

- Back time $=$ delivery time.

- Total loading time $=$ total delivery time + back time .

- Dispatch all products starting from the most profitable to the nearest retailer until it has been satisfied.

- Perform the same procedure of dispatching products to the second-nearest retailer until its entire order has been satisfied, and so on.

- Compute the total number of remaining hours $=$ total number of working hours - total number of hours used to load.

- Calculate profit on the same day using equation (5).

- If the remaining time $\leq$ total loading time, make another trip.

- Otherwise, start delivery on the day next.

- Repeat starting from step 4 until all products have been delivered.

\section{Case study 1}

We consider the ABC Company, which invests in the distribution of perishable products from a central depot to two retailers (Fig. 1). This case considers dynamic perishable products for which the retailer can have multiple orders with varying shelf lives. The case consists of multiple kinds of perishable products where each has a different production cost, shelf life, and rate of deterioration in selling price as shown in Table 1 . The five kinds of products are labeled $\mathrm{P}_{1}, \mathrm{P}_{2}, \mathrm{P}_{3}, \mathrm{P}_{4}$, and $\mathrm{P}_{5}$. Whenever products are saved and kept at the depot, the deterioration rate is considered zero. However, the effects of deterioration typically begin operating on the first day of sale (second day of the receipt of the products), as shown in Table 2. The shelf life is variable, i.e., $\mathrm{P}_{1}$ expires on day 12 but $\mathrm{P}_{5}$ on day 6 . Moreover, the cost of production of each product is variable. $\mathrm{P}_{1}$ has one of the highest production costs while $\mathrm{P}_{5}$ has the lowest. These variables make the investment riskier and complex, especially when the products lose in quality every day.

The expiry day for each product represents a zero value for it, and is thus considered the highest loss in the distribution process. In this case, the distributor devotes too much work and money to keep the perishable products as fresh as possible, or at the highest quality. This aim requires that the distributor deliver the entire stock at once on the first day to guarantee the maximum profit. Because 
Table 1. Parameters of case study 1.

\begin{tabular}{|c|c|c|c|c|c|c|c|c|}
\hline & \multicolumn{3}{|c|}{ Distance (mile) } & \multicolumn{5}{|c|}{ Demand } \\
\hline & $\begin{array}{l}\text { Distribution } \\
\text { Center (DC) }\end{array}$ & Retailer 1 & Retailer 2 & Product 1 & Product 2 & Product 3 & Product 4 & Product 5 \\
\hline Distribution Center & 0 & 90 & 110 & $\mathrm{~N} / \mathrm{A}$ & $\mathrm{N} / \mathrm{A}$ & $\mathrm{N} / \mathrm{A}$ & $\mathrm{N} / \mathrm{A}$ & $\mathrm{N} / \mathrm{A}$ \\
\hline Retailer 1 & 90 & 0 & 50 & 3000 & 2750 & 2900 & 2800 & 3150 \\
\hline Retailer 2 & 110 & 50 & 0 & 2650 & 2800 & 3150 & 2950 & 2800 \\
\hline Shelf life (days) & $\mathrm{N} / \mathrm{A}$ & $\mathrm{N} / \mathrm{A}$ & $\mathrm{N} / \mathrm{A}$ & 12 & 10 & 8 & 7 & 6 \\
\hline Product cost $(\$)$ & $\mathrm{N} / \mathrm{A}$ & $\mathrm{N} / \mathrm{A}$ & $\mathrm{N} / \mathrm{A}$ & 11 & 15 & 6 & 10 & 4 \\
\hline Selling price $(\$)$ & $\mathrm{N} / \mathrm{A}$ & $\mathrm{N} / \mathrm{A}$ & $\mathrm{N} / \mathrm{A}$ & 33 & 45 & 18 & 30 & 12 \\
\hline
\end{tabular}

Table 2. Selling prices including depletion effect.

\begin{tabular}{|c|c|c|c|c|c|c|c|c|c|c|c|c|c|}
\hline \multirow[b]{2}{*}{ Product } & \multicolumn{13}{|c|}{ Day } \\
\hline & 0 & 1 & 2 & 3 & 4 & 5 & 6 & 7 & 8 & 9 & 10 & 11 & 12 \\
\hline $\mathrm{P}_{1}$ & 33 & 30.25 & 27.5 & 24.75 & 22 & 19.25 & 16.5 & 13.75 & 11 & 8.25 & 5.5 & 2.75 & 0 \\
\hline $\mathrm{P}_{2}$ & 45 & 40.5 & 36 & 31.5 & 27 & 22.5 & 18 & 13.5 & 9 & 4.5 & 0 & & \\
\hline $\mathrm{P}_{3}$ & 18 & 15.75 & 13.5 & 11.25 & 9 & 6.75 & 4.5 & 2.25 & 0 & & & & \\
\hline $\mathrm{P}_{4}$ & 30 & 25.71 & 21.42 & 17.14 & 12.85 & 8.57 & 4.28 & 0 & & & & & \\
\hline $\mathrm{P}_{5}$ & 12 & 10 & 8 & 6 & 4 & 2 & 0 & & & & & & \\
\hline
\end{tabular}

the company has limited resources, such as only six vehicles to distribute all products, it is impossible to deliver all of them on the first day.

The objective of this case is to minimize the total cost by delivering all products as soon as possible to guarantee the higher selling prices. A dominant factor in this process is the size of the fleet of vehicles. However, the ABC Company cannot increase the number of vehicles to increase efficiency because this increases the set-off cost of the vehicles.

\subsection{Delivering techniques}

To solve the above case, we propose five delivery techniques and then assess the best way of selling these products at the highest profit. The techniques are direct shipment based on highest daily rate, direct shipment based on shelf life, direct shipment based on the highest selling price, grouping the most profitable products and shipping to the nearest neighbor, and shipping products by using the entire fleet of vehicles to the nearest neighbor. These techniques vary in the sorting of the products and their dispatch. They are explained below.

\subsubsection{Direct shipment based on highest daily rate $(M 1)$}

In this technique, the distributor splits the fleet size into two groups. However, as there are only two retailers and six vehicles, each retailer should assign only three vehicles to deliver and meet all demands. The sequence of deliveries is one where the vehicles leave the central depot fully loaded with products going directly to the retailers. Once they have unloaded the goods, the vehicles must directly return to the central depot to take another load to the retailer if time permits. Time is critical, and should be considered while dispatching and selling perishable goods.

The highest daily rate represents the difference in selling prices between one day and the next for each product. Therefore, we sort products from the highest to the lowest daily rate to maximize total profit. We thus obtain the sequence of the five products as $\left(\mathrm{P}_{2}-\mathrm{P}_{4^{-}}-\mathrm{P}_{1^{-}}-\mathrm{P}_{3^{-}}\right.$ $\mathrm{P}_{5}$ ), and this is illustrated in Table 2 .

From Table 2, note that the greatest difference between days for all products is in P2. However, that rate is $4.5 \%$, represents the highest daily drop among all products, and it should be considered first as the most profitable product.

In this method of distribution, the shortest and easiest way to dispatch goods is to deliver them directly. Moreover, when shipping the most profitable product, total profit should always be maximum. But when freshness and thus quality are continuously lost, prices drop quickly depending on each product's selling price and shelf life. The zeros in Table 2 represent significant loss for each product price until it illustrate products price reaches zero on the last day of its lifetime.

\subsubsection{Direct shipment based on shelf life (M2)}

Vehicles used for direct shipment must be fully loaded and travel directly from the central depot to the retailers, where time is the most dominant factor in this cold chain. The shelf life of each product is considered instead of is rate of profit as in $M 1$. Hence, the sequence and priority of loading products into vehicles are based on the shortest shelf life. Thus, the shortest shelf life the first product delivered, the one with the second-shortest shelf life is the second product 
Table 3. Product cost, price, and shelf life.

\begin{tabular}{llll}
\hline Product & Cost & Selling price & Shelf life \\
\hline $\mathrm{P}_{1}$ & 11 & 33 & 12 \\
$\mathrm{P}_{2}$ & 15 & 45 & 10 \\
$\mathrm{P}_{3}$ & 6 & 18 & 8 \\
$\mathrm{P}_{4}$ & 10 & 30 & 7 \\
$\mathrm{P}_{5}$ & 4 & 12 & 6 \\
\hline
\end{tabular}

Table 4. Profit rate.

\begin{tabular}{lll}
\hline Product & Rate\% & Order \\
\hline $\mathrm{P}_{1}$ & 2.75 & 3 \\
$\mathrm{P}_{2}$ & 4.5 & 1 \\
$\mathrm{P}_{3}$ & 2.25 & 4 \\
$\mathrm{P}_{4}$ & 4.28 & 2 \\
$\mathrm{P}_{5}$ & 2 & 5 \\
\hline
\end{tabular}

delivered, and so on. In this case, the sequence of products is $\left(\mathrm{P}_{5}-\mathrm{P}_{4}-\mathrm{P}_{3}-\mathrm{P}_{2}-\mathrm{P}_{1}\right)$. Table 3 represents the products' shelf lives, cost, and selling price excluding the effects of deterioration.

In Table 3, note that the product with the longest shelf life has among the highest selling prices, but product 5 with the shortest shelf life has the lowest selling price and lowest cost. This can limit this method from obtaining a high profit, as mentioned in the next part of the case analysis.

\subsubsection{Direct shipment based on the highest selling price (M3)}

The manner of distributing products is similar here to that mentioned above, but the sorting is based on the product's selling price. The product with the highest selling price is loaded and delivered first. As shown in Table 3 , the sequence for this method is $\left(\mathrm{P}_{2}-\mathrm{P}_{1^{-}}-\mathrm{P}_{4^{-}}-\mathrm{P}_{3^{-}}\right.$ $\mathrm{P}_{5}$ ). Without the effect of the rate of deterioration, this method is considered the best as the first product sold is the most profitable.

\subsubsection{Grouping the most profitable products and shipping to the nearest neighbor (M4)}

In this method, we first group all products based on the rates of profit listed in Table 4 . Therefore, $\mathrm{P}_{2}$, and $\mathrm{P}_{4}$ can be merged together, as can $\mathrm{P}_{1}$ and $\mathrm{P}_{3}$. $\mathrm{P}_{5}$ then is the only product remaining in the group. Table 5 represents all products in different groups.

The method of distribution involves using the group with the highest rate of profit and loading its member with the highest profit into vehicles. Here, $\mathrm{G}_{1}$ is the best group to start with because it contains the two most profitable products. In $\mathrm{G}_{1}$ the first product to be loaded is $\mathrm{P}_{2}$, and so on.
Table 5. Grouping products.

\begin{tabular}{lll}
\hline Product & Rate & Group \\
\hline $\mathrm{P}_{2}$ & 4.5 & $\mathrm{G}_{1}$ \\
$\mathrm{P}_{4}$ & 4.28 & $\mathrm{G}_{1}$ \\
$\mathrm{P}_{1}$ & 2.75 & $\mathrm{G}_{2}$ \\
$\mathrm{P}_{3}$ & 2.25 & $\mathrm{G}_{2}$ \\
$\mathrm{P}_{5}$ & 2 & $\mathrm{G}_{3}$ \\
\hline
\end{tabular}

Table 6. Results of all methods.

\begin{tabular}{lll}
\hline Delivering technique & Total cost & Total revenue \\
\hline M1 & $3,63,200$ & $4,91,367.9$ \\
$M 2$ & $3,80,800$ & $4,01,058.9$ \\
M3 & $3,63,200$ & $4,79,082.1$ \\
$M 4$ & $3,58,800$ & $4,90,975$ \\
M5 & $3,69,100$ & $4,94,641.07$ \\
\hline
\end{tabular}

In this type of transportation, all vehicles work together and are not divided among retailers. Therefore, all six vehicles travel to the nearest retailer from the central depot to serve it with the most profitable product from the highest profitable group. When the nearest retailer is completely satisfied with the first group, the vehicles move to the next-nearest retailer to the central depot. Once again, all vehicles start over to serve the nearest retailer with the second group, and then shift to the second retailer, and so on.

\subsubsection{Shipping products by entire fleet to the nearest neighbor (M5)}

In this method, the products are sorted from the most profitable to the least as shown in Table 4 . The product sequence is thus $\left(\mathrm{P}_{2}-\mathrm{P}_{4}-\mathrm{P}_{1}-\mathrm{P}_{3}-\mathrm{P}_{5}\right)$. The delivery process simply starts loading products in order into the vehicles and sends the entire fleet to the nearest retailer from the central depot. Once the nearest retailer has been satisfied, the vehicles shift to supply the next retailer farthest one from the central depot. There is a strong correlation among time, demand, and vehicle capacity, because of which the second retailer might not get the products on the first day, in particular when the first retailer makes a large demand, and the number and capacity of vehicles are small. However, in this method, the only way and appropriate estimated time to move the products to the next retailer is when the first one has been satisfied.

\subsection{Results}

In this subsection we analyze the results of all five delivering techniques described above as well as the models proposed in Section 2. Having applied each method using the data in Table 1, the results of the total cost and total 


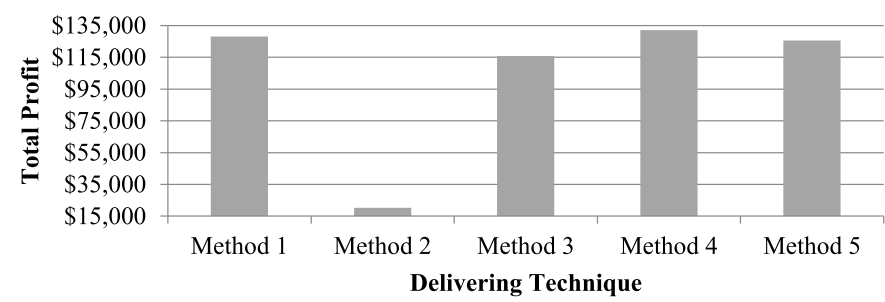

Fig. 2. Total profit.

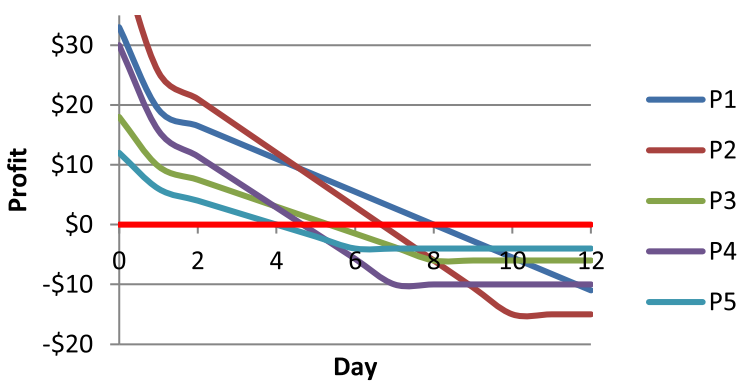

Fig. 3. Depreciation in profit for each product.

revenue of all products are presented in Table 6 . They show that the company can achieve the maximum profit by applying method four (M4), grouping the most profitable products and shipping to the nearest neighbor (Fig. 2). Figure 3 shows the depreciation in profit for each product with time. It also shows that profit changed into cost if the product was not delivered before its shelf life expired.

\subsection{Analysis of results}

The total number of available working hours per day is only eight, which this limits the round trip to retailer 2 . We calculate the total traveling time by dividing the distance by constant vehicle speed, 60 miles per hour. The distance between the depot and retailer 1 is thus 90 miles the time taken to deliver is an hour and a half. The time taken to return from the retailer to the depot is the same, plus the service time, which is assumed to be one hour per retailer per load. Hence, the total time taken on retailer 1 for a round trip was four hours. Under this constraint, each truck can make two round trips for retailer 1 in eight hours. By contrast, the distance between the depot and retailer 2 is 110 miles, and thus the time needed to service it for each truck is $4.66 \mathrm{~h}$. Thus, each vehicle can make only one round trip. The total serving time for retailer 2 $(4.66 \mathrm{~h})$ is obtained by dividing 110 miles by $60 \mathrm{~m} / \mathrm{h}$, and adding the service time and the time taken for the trip back from retailer 2 to the depot. Therefore, serving retailer 2 incurs a significant delay. Nothing can be done about this because the total number of working hours is fixed. This method is helpful, and invariably yields good values because it consumes all its time for retailer 1 without any delay. By combining the highest profitable sequence with direct shipping, we obtain the secondhighest total profit after the groping method. Table 7 illustrates calculations of the traveling time and the service time between all facilities.
Table 7. Total time taken to move between depot and retailers.

\begin{tabular}{llllll}
\hline Distance & $\begin{array}{l}\text { Average } \\
\text { speed }\end{array}$ & $\begin{array}{l}\text { Delivery } \\
\text { time }\end{array}$ & $\begin{array}{l}\text { Back } \\
\text { time }\end{array}$ & $\begin{array}{l}\text { Service } \\
\text { time }\end{array}$ & $\begin{array}{l}\text { Total } \\
\text { time }\end{array}$ \\
\hline 90 & 60 & 1.5 & 1.5 & 1 & 4 \\
110 & 60 & 1.83 & 1.83 & 1 & 4.67 \\
\hline
\end{tabular}

For each method, the difference between the retailers in terms of total cost, revenue, and profit is significant owing to the different delivering techniques. Even when using the same method, the total time and rate of deterioration for each retailer had a significant influence. Table 8 demonstrates the differentness among all methods for both retailers.

Table 6 shows that all costs are very close for all methods but their revenues by selling products fluctuated. The highest cost for each product was obtained for $M 2$ (shipping based on shelf life). This significant cost was incurred for two reasons. First, distributing products with the shortest shelf lives and lowest selling price first is not always a good strategy. However, time is of the essence, and the selling price of each product drops every day. In other words, the earlier the delivery, the higher the profit is. Thus, wasting the opportunity to deliver and selling products on the first two days leads to a significant loss of total profit. Distributing perishable products based on shelf life can sometimes be beneficial but not in this case, where the initial time (i.e., the first two days) is wasted by transporting least profitable product, $\mathrm{P}_{5}$. The second reason for the large cost was the distance between retailer 2 and the central depot. Because of this, twice the time needed to service retailer 1 was needed to deliver to retailer 2. The results show loss from the second day of distribution to retailer 2 , but retailer 1 experiences a loss with the last truck on the final delivery day. Table 9 illustrates the results of delivering products to retailer 2 by the second method, direct shipment based on the products' shelf lives.

Among the highest revenues and profits listed in Table 6 are obtained by $M 1$, which involves directly dispatching the most profitable products sorted as $\left(\mathrm{P}_{2^{-}}-\mathrm{P}_{4^{-}}\right.$ $\left.\mathrm{P}_{1}-\mathrm{P}_{3}-\mathrm{P}_{5}\right)$. The revenue is high because retailer 1 is very close to the central depot, thus allowing the assigned vehicles to make two round trips per day. This expedites delivery with a minimal loss of products. Retailer 1 thus consumes exactly half the time of retailer 2 (five days versus 10). However, retailer 2 is farther than retailer 1 from the central depot, and thus incurs higher cost. The difference between the two methods is only in the sequence of delivery of products, and leads to a significant loss to retailer 2 for M2. $M 2$ for retailer 2 does not make any profit from day 4 onward. It suffers some loss on day 2 but earns a profit on day 3 . Once there is no profit from day 4 , the company tries to get rid of the stock by selling all products anyway. Table 9 shows the significance of the loss to retailer 2 in $M 2$.

In $M 3$, the method of distributing products to both retailers is identical to that in the first two methods, but the sequence of products is different. Table 2 shows that the 
Table 8. Costs, revenues, and profits for both retailers.

\begin{tabular}{lllll}
\hline Method & Retailer & Total cost & Total revenue & Total profit \\
\hline \multirow{2}{*}{$M 1$} & R1 & $1,86,250$ & $2,82,446.4$ & $96,196.43$ \\
& R2 & $1,76,950$ & $2,08,921.4$ & $31,971.43$ \\
2 & R1 & $1,86,250$ & $2,57,712.5$ & $71,462.5$ \\
& R2 & $1,94,550$ & $1,43,346.4$ & $-51,203.6$ \\
$M 3$ & R1 & $1,86,250$ & $2,78,146.4$ & $91,896.43$ \\
$M 4$ & R2 & $1,76,950$ & $2,00,935.7$ & $23,985.71$ \\
$M 5$ & N/A & $3,58,800$ & $4,90,975$ & $1,32,175$ \\
& N/A & $3,69,100$ & $4,94,641.1$ & $1,25,541.1$ \\
\hline
\end{tabular}

Table 9. Sample data of $M 2$.

\begin{tabular}{llll}
\hline Delivery day & Total cost & Total revenue & Total profit \\
\hline 2 & 4200 & 4000 & -200 \\
4 & 7200 & 6428.57 & -771.43 \\
5 & 5200 & 3375 & -1825 \\
6 & 5200 & 2250 & -2950 \\
7 & 9700 & 6750 & -2950 \\
8 & 9700 & 4500 & -5200 \\
9 & 7700 & 4125 & -3575 \\
10 & 7700 & 2750 & -4950 \\
\hline
\end{tabular}

Table 10. Sample values of retailer 2 for $M 3$.

\begin{tabular}{llll}
\hline Delivery day & Total cost & Total revenue & Total profit \\
\hline 4 & 7200 & 6428.57 & -771.43 \\
5 & 7200 & 4285.71 & -2914.29 \\
6 & 7200 & 2142.857 & -5057.14 \\
7 & 5200 & 1125 & -4075 \\
8 & 3000 & 0 & -3000 \\
9 & 2000 & 0 & -2000 \\
10 & 2000 & 0 & -2000 \\
\hline
\end{tabular}

sequence of products based on highest selling price is $\left(\mathrm{P}_{2}-\mathrm{P}_{1}-\mathrm{P}_{4}-\mathrm{P}_{3}-\mathrm{P}_{5}\right)$. The result of this method is moderately satisfactory, and never beats the first method (based on the highest daily rate). The reason of getting low profit comparing to the sequence of products that start with the highest selling price is there is no profit for both retailers since day 4 starting. In other words, neither retailer makes any money from day 4 onward, and so wants to get rid of its stock to get some money back. Table 10 shows randomly chosen results for retailer 2 in $M 3$.

Table 10 demonstrates the significant loss incurred by this method. However, from days 8 to $10, \mathrm{P}_{3}$ and 5 expired before they could be sold. Therefore, the costs $(3000,2000$, and 2000) are those of the products.

In $M 5$, the entire fleet of vehicles operates together and starts delivering from the central depot to the nearest retailer. The vehicles (six vehicles) are loaded starting with $\mathrm{P}_{2}$, and the same sequence as in method 1 is maintained:
Table 11. Sample values for $M 5$.

\begin{tabular}{llll}
\hline Delivery day & Total cost & Total revenue & total profit \\
\hline 1 & 9300 & 20,250 & 10,950 \\
2 & 7300 & 13,750 & 6450 \\
3 & 3800 & 3000 & -800 \\
4 & 7200 & 6428.57 & -771.43 \\
5 & 7200 & 4285.71 & -2914.29 \\
6 & 7700 & 8250 & 550 \\
7 & 5200 & 1125 & -4075 \\
8 & 2000 & 0 & -2000 \\
\hline
\end{tabular}

$\left(\mathrm{P}_{2}-\mathrm{P}_{4}-\mathrm{P}_{1}-\mathrm{P}_{3}-\mathrm{P}_{5}\right)$. Once retailer 1 has been satisfied, retailer 2 starts receiving products. There is some loss before profit is made, followed by a cost incurred. This fluctuation in cost and profit is caused by the effect of the deterioration rates and the cost of transportation. However, if the latter is higher than the selling price, it increases the total cost and accordingly reduces the total profit. Table 11 illustrates this using some random values for this method.

In this case, the most profitable method is M4: grouping products together. However, the method is based on similarities among the profit ratios of products for both retailers. We thus sort products from the most profitable to the least as $\left(\mathrm{P}_{2}-\mathrm{P}_{4}-\mathrm{P}_{1}-\mathrm{P}_{3}-\mathrm{P}_{5}\right)$. The first group consists of $\mathrm{P}_{2}$ and $\mathrm{P}_{4}$ representing the highest ratios. The distribution is by group for both retailers, starting with the one nearest to the central depot. This process gives good values until the end of the first round trip on day 4 . On day 5 , there is a loss in $\mathrm{P}_{3}$ for retailer 1 because of the rate of deterioration of $\mathrm{P}_{4}$ on day 4 (see Tab. 2). On the next day, we note that $\mathrm{P}_{1}$ yields good profit because its selling price on day $5(\$ 19.25)$ is much higher than that of $\mathrm{P}_{3}$ on day 4 only $(\$ 9)$. Because $\mathrm{P}_{1}$ has the longest shelf life, $\mathrm{P}_{3}$ can yield one-third of its original price until day $8 . \mathrm{P}_{1}$ is thus considered a rescue product that can help in the intervening days. For all of day 6 , there is a significant loss in selling $\mathrm{P}_{3}$, but the company wants to get rid of it and get some cash in return before it expires. On days 7 and 8 , the company cannot make any money or deliver any item of $\mathrm{P}_{5}$ because it has expired, and thus incurs the cost of its production. In Table 2, we see that $\mathrm{P}_{5}$ expires on day 6 such that there is no benefit or profit expected on days after it. 
Table 12. Demand for scenario B.

\begin{tabular}{llll}
\hline Product & Retailer 1 & Retailer 2 & Total \\
\hline $\mathrm{P}_{1}$ & 1050 & 1150 & 2200 \\
$\mathrm{P}_{2}$ & 1100 & 1200 & 2300 \\
$\mathrm{P}_{3}$ & 1350 & 1100 & 2450 \\
$\mathrm{P}_{4}$ & 1150 & 1300 & 2450 \\
$\mathrm{P}_{5}$ & 1200 & 1250 & 2450 \\
Total & 5850 & 6000 & 11,850 \\
\hline
\end{tabular}

Table 13. Demand for scenario C.

\begin{tabular}{llll}
\hline Product & Retailer 1 & Retailer 2 & Total \\
\hline $\mathrm{P}_{1}$ & 5000 & 4850 & 9850 \\
$\mathrm{P}_{2}$ & 4000 & 3800 & 7800 \\
$\mathrm{P}_{3}$ & 3950 & 4100 & 8050 \\
$\mathrm{P}_{4}$ & 4200 & 4000 & 8200 \\
$\mathrm{P}_{5}$ & 3800 & 4200 & 8000 \\
Total & 20,950 & 20,950 & 41,900 \\
\hline
\end{tabular}

Table 14. Demand for scenario D.

\begin{tabular}{llll}
\hline Product & Retailer 1 & Retailer 2 & Total \\
\hline $\mathrm{P}_{1}$ & 5150 & 2950 & 8100 \\
$\mathrm{P}_{2}$ & 4900 & 3400 & 8300 \\
$\mathrm{P}_{3}$ & 4850 & 2800 & 7650 \\
$\mathrm{P}_{4}$ & 5250 & 3200 & 8450 \\
$\mathrm{P}_{5}$ & 5150 & 3150 & 8300 \\
Total & 25,300 & 15,500 & 40,800 \\
\hline
\end{tabular}

Table 15. Demand for scenario E.

\begin{tabular}{llll}
\hline Product & Retailer 1 & Retailer 2 & Total \\
\hline $\mathrm{P}_{1}$ & 2950 & 5150 & 8100 \\
$\mathrm{P}_{2}$ & 3400 & 4900 & 8300 \\
$\mathrm{P}_{3}$ & 2800 & 4850 & 7650 \\
$\mathrm{P}_{4}$ & 3200 & 5250 & 8450 \\
$\mathrm{P}_{5}$ & 3150 & 5150 & 8300 \\
Total & 15,500 & 25,300 & 40,800 \\
\hline
\end{tabular}

Table 16. Total profits of all methods in all scenarios.

\begin{tabular}{lllll}
\hline Delivering techniques & Scenario B & Scenario C & Scenario D & Scenario E \\
\hline$M 1$ & $1,01,576.8$ & $1,08,612.5$ & $1,25,283.93$ & $57,103.571$ \\
$M 2$ & 90,375 & $-1,14,323.2$ & $-92,803.57$ & $-1,31,589.3$ \\
$M 3$ & $99,657.14$ & $1,06,807.14$ & $1,04,294.64$ & $85,937.5$ \\
$M 4$ & $94,823.21$ & $1,20,085.7$ & $1,40,010.7$ & $88,507.14$ \\
$M 5$ & $1,04,216.1$ & $1,01,280.4$ & $92,096.43$ & $81,346.43$ \\
\hline
\end{tabular}

\subsection{Case study 2}

In this subsection, we apply four scenarios (B, C, D, and E) to the same problem as above to test and verify our proposed method. The first scenario involved a smaller quantity than before. Table 12 provides the data for scenario B, where the demanded quantity was nearly less than half the demand in case study 1.

For this scenario B, M5, shipping all products at once directly to the nearest retailer from the central depot, yielded the highest profit. The second-highest value resulted from $M 1$, where shipping is based on the highest daily rate of profit. The method based on shelf life comes third in this scenario because the quantity involved is small, and retailer 1 distributes all its products in two days (two round trips each day). However, retailer 2 needs four days to distribute all products. In general, a smaller quantity yields different results for different methods because of the effect of time and the limited number of vehicles.

In scenario $\mathrm{C}$, the demanded quantity was almost twice that in case study 1 . Table 13 shows the same demanded quantity for both retailers 1 and 2 .
In this scenario featuring high demand, we obtain the highest value for $M 4$, grouping products together in the same manner as in $M 1$. However, distribution by shelf life is infeasible because it leads to a loss on the whole. The second-highest values were obtained in $M 1$, followed by $M 3$ and $M 5$.

The next two scenarios featured the same quantity as before, but retailer 1 has demands a greater quantity in one scenario (D) and retailer 2 demands more the other (E). Tables 14 and 15 show the demanded quantities for both scenarios D and E.

In both scenarios, we obtain the highest values using the grouping method (M4), but the method invoking the shelf life (M2) remains infeasible. The second-highest value in scenario D is obtained using $M 1$, followed by $M 3$ and $M 5$. By contrast, in scenario $E$, the second-highest value is obtained using $M 3$, which is based on the highest selling price. $M 5$ for scenario $\mathrm{E}$ is second to last, and $M 1$ delivers the poorest performance because the quantity demanded by retailer 2 , which is far from the central depot, is large. Table 16 illustrates all results for all methods and scenarios. Figure 4 compares profits made in all scenarios as well as delivering techniques. It shows that grouping the most 


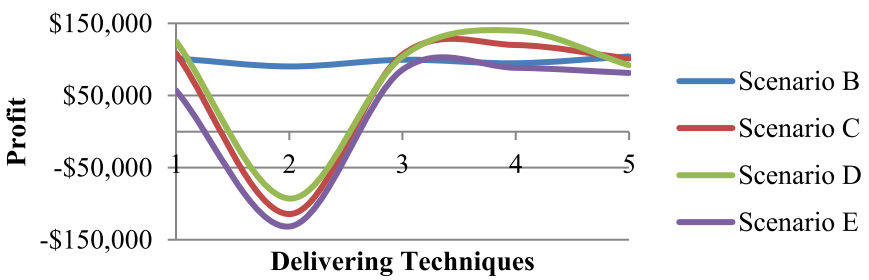

Fig. 4. Comparison of profits of all scenarios and delivering techniques.

profitable products and shipping to the nearest neighbor is the most profitable method that can fit and benefit most scenarios.

\section{Conclusion}

The supply chain an important component of business operations worldwide. Joining facilities to deliver fresh vegetables and perishables to the end customer is a complex process that requires care. This chain is an integration of different entities, such as the grower (farm), packing shade, distribution center (wholesaler), store, and end customer. Transportation is a major part of the supply chain that poses many challenges. This paper proposed heuristics models to deliver to the retailer based on the effect of degradation in the quality and prices of perishables. Five heuristics with deferent scenarios were modeled and analyzed to determine the best one. Each featured a situation different from the others. The heuristics considered were direct shipment based on highest daily rate of profit, direct shipment based on shelf life, direct shipment based on the highest selling price, grouping the most profitable products and shipping to the nearest neighbor, and shipping products using the entire fleet of vehicle to the nearest neighbor. The results show that the best heuristic for distributing multiple kinds of perishable products to maximize profit is to group the most profitable products and transport them to the nearest retailer. The work here can be extended to include more elements and methods, such as weight and total cost, to enhance the optimization techniques. Moreover, different scenarios can be applied to further test the effectiveness of the proposed method, and more data need to be collected from different wholesalers to apply to the proposed model. Other techniques such as the genetic algorithm can be used to generate solutions more quickly.

The authors thank the Deanship of Graduate Studies and Scientific Research at Effat University for its support.

\section{References}

1. R.O. Bahebshi,A.T. Almaktoom, Dynamical modeling of fresh vegetables while considering degradation effect on pricing, in 7th Annual Conference on Industrial Engineering and Operations Management, IEOM 2017 (2017), pp. 1817-1825

2. J.T. Mentzer, W. DeWitt, J.S. Keebler, S. Min, N.W. Nix, C.D. Smith, Z.G. Zacharia, Defining supply chain management, J. Bus. Logist. 22, 1 (2001)

3. T. Davis, Effective supply chain management, Sloan Manag. Rev. 34, 35 (1993)
4. K. Mehdi, M. Salahi, A. Jamalian, The capacitated plant location problem with customer and supplier matching and interval demands uncertainty, Int. J. Simulat. Multidiscipl. Des. Optim. 5, A03 (2014)

5. A.K. Alsaadi, A.T. Almaktoom, K.K. Krishnan, Reliability evaluation and design optimization of inventory management system, in Proceedings of the International Conference on Industrial Engineering and Operations Management (2016), pp. 922-927

6. P. Wang, Z. Wang, A.T. Almaktoom, Dynamic reliabilitybased robust design optimization with time-variant probabilistic constraints, Eng. Optim. 46, 784 (2014)

7. A.T. Almaktoom, K.K. Krishnan, P. Wang, S. Alsobhi, Assurance of system service level robustness in complex supply chain networks, Int. J. Adv. Manuf. Technol. 74, 445 (2014)

8. S. Raczynski, A market model: uncertainty and reachable sets, Int. J. Simul. Multidiscipl. Des. Optim. 6, A2 (2015)

9. K.K. Krishnan, A.T. Almaktoom, P. Udayakumar, Optimisation of stochastic assembly line for balancing under high variability, Int. J. Ind. Syst. Eng. 22, 440 (2016)

10. X. Cai, J. Chen, Y. Xiao, X. Xu, Optimization and coordination of fresh product supply chains with freshnesskeeping effort, Prod. Oper. Manag. 19, 261 (2010)

11. A.T. Almaktoom, K.K. Krishnan, P. Wang, S. Alsobhi, Cost efficient robust global supply chain system design under uncertainty, Int. J. Adv. Manuf. Technol. 85, 853 (2016)

12. A.T. Almaktoom, Stochastic reliability measurement and design optimization of an inventory management system, Complexity (2017)

13. B. Deniz, Essays on perishable inventory management. Doctoral dissertation, Tepper School of Business, Carnegie Mellon University, Pittsburgh, 2007

14. K.H. Widodo, H. Nagasawa, K. Morizawa, M. Ota, A periodical flowering-harvesting model for delivering agricultural fresh products, Eur. J. Oper. Res. 170, 24 (2006)

15. X. Wang, Z. Fan, Y. Wang, M. Li, A laboratory exploration for multi-period perishable food pricing, Br. Food J. 117, $2214(2015)$

16. A. Osvald, L.Z. Stirn, A vehicle routing algorithm for the distribution of fresh vegetables and similar perishable food, J. Food Eng. 85, 285 (2008)

17. H.K. Chen, C.F. Hsueh, M.S. Chang, Production scheduling and vehicle routing with time windows for perishable food products, Comput. Oper. Res. 36, 2311 (2009)

18. J. Blackburn, G. Scudder, Supply chain strategies for perishable products: the case of fresh produce, Prod. Oper. Manag. 18, 129 (2009)

19. M. Shukla, S. Jharkharia, Agri-fresh produce supply chain management: a state-of-the-art literature review, Int. J. Oper. Prod. Manag. 33, 114 (2013)

20. A. Rong, R. Akkerman, M. Grunow, An optimization approach for managing fresh food quality throughout the supply chain, Int. J. Prod. Econ. 131, 421 (2011)

21. X. Cai, J. Chen, Y. Xiao, X. Xu, G. Yu, Optimal decisions of the manufacturer and distributor in a fresh product supply chain involving long-distance transportation, in Handbook of Newsvendor Problems (Springer, New York, 2012), p. 315

22. R. Li, H. Lan, J.R. Mawhinney, A review on deteriorating inventory study, J. Serv. Sci. Manag. 3, 117 (2010)

23. F. Raafat, Survey of literature on continuously deteriorating inventory models, J. Oper. Res. Soc. 42, 27 (1991) 
24. A. Federgruen, G. Prastacos, P.H. Zipkin, An allocation and distribution model for perishable products, Oper. Res. 34, 75 (1986)

25. C.D. Tarantilis, C.T. Kiranoudis, Distribution of fresh meat, J. Food Eng. 51, 85 (2002)

26. C.I. Hsu, S.F. Hung, H.C. Li, Vehicle routing problem with time windows for perishable food delivery, J. Food Eng. 80, 465 (2007)

27. S. Zanoni, L. Zavanella, Single-vendor single-buyer with integrated transport-inventory system: models and heuristics in the case of perishable goods, Comput. Ind. Eng. 52, 107 (2007)

28. X. Xunyu, M. Tomohiro, Perishable goods delivery and scheduling with time window by genetic algorithm, in 2010 IEEE International Conference on Automation and Logistics (2010), p. 587

29. K. Govindan, A. Jafarian, R. Khodaverdi, K. Devika, Twoechelon multiple-vehicle location-routing problem with time windows for optimization of sustainable supply chain network of perishable food, Int. J. Prod. Econ. 152, 9 (2014)

Cite this article as: Raghad O. Bahebshi, Abdulaziz T. Almaktoom, Heuristic dynamic approach to perishable products in presence of deterioration effect, Int. J. Simul. Multidisci. Des. Optim. 10, A12 (2019) 